\title{
Human Rights and Social Stigma Review for Leprosy Patients in Korea
}

\author{
Seungshin Lee ${ }^{1,2}$, David Ahn², Justin Kim², Cathy Park², Kunmin Kim², Alice Kim², \\ Chae Eun Kim², Jisu Shin'2, Timothy Cho², Jonathan Jo², David Park', Tae Youn Kim², \\ Paul S. Chung, ${ }^{2 *}$
}

${ }^{1}$ School of Medicine, University of California, Irvine, CA, USA

${ }^{2}$ Youth with Talents, Fairfax, VA, USA

${ }^{3}$ Fuzbien Technology Institute, Rockville, MD, USA

Email: *paulschung08@gmail.com

How to cite this paper: Lee, S., Ahn, D., Kim, J., Park, C., Kim, K., Kim, A., Kim, C.E., Shin, J., Cho, T., Jo, J., Park, D., Kim, T.Y. and Chung, P.S. (2021) Human Rights and Social Stigma Review for Leprosy Patients in Korea. Advances in Infectious Diseases, 11, 73-83.

https://doi.org/10.4236/aid.2021.111009

Received: April 16, 2020

Accepted: March 20, 2021

Published: March 23, 2021

Copyright $\odot 2021$ by author(s) and Scientific Research Publishing Inc. This work is licensed under the Creative Commons Attribution International License (CC BY 4.0).

http://creativecommons.org/licenses/by/4.0/

\section{(c) (i) Open Access}

\begin{abstract}
Leprosy is a chronic disease caused by a low multiplying bacillus, Mycobacterium leprae, which primarily affects the skin and the extremities. Multidrug therapy (MDT) and Bacillus Calmette-Guérin (BCG) vaccinations are effective at treatment of the disease, but social misconceptions about the disease inhibit efficient health care for affected individuals. In South Korea, leprosy patients face social, economic, and political discrimination. Korean leprosy patients are isolated into Sorokdo island and face challenges such as difficulty receiving education and limited job opportunities. Leprosy cognitively, emotionally, and socially impacts patients' lives, and represents a serious social inequality issue. To raise awareness, dispel myths about the disease, and to end patient discrimination that destroys families, we conducted case studies based on scientific journals. The paper specifically focuses on difficulties faced by Korean leprosy patients, and subsequent initiatives by the government to aid patients. To reach the WHO's target of health and wellbeing for all by 2030 , we need to educate the masses about leprosy and address relevant social inequality issues.
\end{abstract}

\section{Keywords}

Leprosy, Sorokdo

\section{Introduction}

\section{History and Origins of Leprosy:}

Leprosy (Hansen's Disease) is a chronic neurological disease caused by a pa- 
thogen, Mycobacterium leprae, a close relative of the tubercle bacillus [1]. $M$. Leprae has the longest doubling time of all known bacteria and has thwarted every effort at culture in the laboratory. The bacteria's incubation period is about 5 years and it can take as long as 20 years for the symptoms to appear [2]. The prevalence of leprosy has been reduced extensively by the World Health Organization (WHO) through Multi-Drug Therapy (MDT) and Bacillus Calmette-Guérin (BCG) vaccinations, but incidences of this disease continue to occur with more than 690,000 new cases reported annually [1]. Means of transmission remain uncertain, but like tuberculosis, leprosy infection is thought to spread by the respiratory route, because lepromatous patients harbor bacilli in their nasal passages [1]. The bacterium accumulates in the extremities of the body where it resides within the macrophage and infects the Schwann cells of the peripheral nervous system [1]. Lack of myelin production by infected Schwann cells and their destruction by host-mediated immune reactions lead to nerve damage, sensory loss, and disfiguration which are the hallmarks of leprosy.

Ancient texts describe the existence of leprosy in China, India, and Egypt in about $600 \mathrm{BC}$, and skeletal remains bearing hallmarks of the disease that have been found in Egypt [3]. Leprosy is believed to have originated in the Indian subcontinent and to have been introduced into Europe by Greek soldiers returning from the Indian campaign of Alexander the Great [3]. From Greece, the disease is thought to have spread around the Mediterranean basin, with the Romans introducing leprosy into the Western part of Europe [3]. Little is known about its presence in sub-Saharan Africa except that the disease was present prior to the colonial era. From India, leprosy is thought to have spread to China and then to Japan and Korea, reaching the Pacific Islands like New Caledonia as recently as the $19^{\text {th }}$ century [3]. In 1873, Armauer Hansen discovered the leprosy bacillus in skin biopsies but failed to culture M. leprae [3]. Possibly due to its exceptionally slow growth of the bacillus, which has a doubling time of 14 days, multiplying the bacteria in synthetic media seemed impossible, though metabolic activity can be detected [1]. It was only when it was discovered that the nine-banded armadillo, Dasypus novemcinctus, could be infected that sufficient quantities of $M$. leprae were obtained for biological and immunological analysis [3].

\section{Challenges of Leprosy:}

Leprosy is two conjoined diseases [4]. The first is a chronic mycobacterial infection that elicits an extraordinary range of cellular immune responses in humans [4]. The second is a peripheral neuropathy that is initiated by the infection and its accompanying immunologic events, but whose course and sequelae often extend many years beyond the cure of the infection and may have severely debilitating physical, social, and psychological consequences [4]. Effective multidrug regimens are now used worldwide, and the infection in individuals is curable [4]. While the reported number of registered cases worldwide has declined in the last two decades, the reported number of new cases registered each year has remained the same (at 500,000 to 700,000) over the same interval [4]. In some 
countries where leprosy is endemic, the number of new cases actually appears to be increasing, while in others decreasing trends are reported [4]. Mathematical modeling of the potential decline in leprosy incidence and prevalence, using various premises regarding the efficacy of treatment and prevention, suggests that the diseases will remain a major public health problem for at least several decades [4]. Leprosy remains a medical and scientific challenge of the first order, even though support for research on these diseases has declined substantially as other conditions have assumed greater global priority [4].

There are some inherent risk factors associated with leprosy. Those who have close and long-term contact with leprosy patients tend to have higher risk factors of developing leprosy [5]. Furthermore, when a close genetic relationship such as siblings, children, and parents was grouped together, there was an indication of increased risk [5]. However, multidrug therapy, which was recommended for leprosy by the WHO starting in 1981, has proven effective at improving treatment efficacy and overcoming problems caused by drug-resistant strains of $M$. leprae [4]. Multidrug therapy has been very practical and successful in treatment of both multibacillary (MB) and paucibacillary (PB) leprosy [4]. Despite being cured through multidrug therapy, people with leprosy are often discriminated by society and the government, and encounter difficulty in getting married, receiving education and obtaining job opportunities. This paper focuses specifically on the corollaries faced by Korean leprosy patients due to their physical abnormalities and demonstrates that currently, leprosy is more of a psychosocial problem than a public health problem.

\section{Leprosy Patients' Life in Korea}

For the past century, Leprosy patients have been targeted for discrimination as they have lived in a special, segregated social group in our society. During the Japanese Colonial period, colonial authorities took a strict quarantine policy and blocked any exposure of Leprosy disease to healthy civilians. Thus, during the time of Japanese rule (1910-1945), leprosy patients in Korea were exiled to Sorok Island [6]. The island was used as a prison camp for these patients, and hospital workers forced them into sterilizations and abortions [6]. Hansen's disease patients were heavily discriminated even by the Japanese clinicians [6]. Patients were forced to receive unnecessary surgeries such as abortions and vasectomies, and to work under violence [6]. Their corpses were used for experimentations [6]. Even after Japan's rule in 1945, patients' conditions did not improve. Recent investigations confirmed a 1948 slaughter of 84 leprosy patients [6].

South Korea abolished its anti-leprosy segregation policy in 1963, but human rights abuses on the island continued for decades [7]. Government officials continued to relocate leprosy patients to the island as recently as 1991 [6]. In 2009, a bridge was built to connect Sorok Island and the mainland of Korea [6]. The bridge was used to end isolation and segregation, but the public's distrust about patients' disfigurements remains [6]. Some patients refuse to leave the island, 
feeling unwelcomed by society, and many that have fled the island are returning [7]. Most returnees to the island are cured of leprosy, and free to live wherever they choose but chose the life in Sorok Island facing outside prejudices against leprosy [7]. For instance, Yu Myung-Sun, 61, who lived on Sorok until 1974, returned in 2008 after living with other former leprosy sufferers in a village near Seoul [7]. "People outside the village wouldn't even look at me," Yu said. "Restaurants wouldn't sell meals to us [7]." Despite being cured, she continues to wear a big pair of sunglasses to cover up black spots on her face caused by anti-leprosy medication [7]. Yu is one example of the discrimination that leprosy patients face. Active leprosy communities still exist in several countries including India, China, and Vietnam, and discrimination continues to plague those maimed by the age-old disease [7].

\section{Stigma about Leprosy}

According to Dr. Erwin Cooreman, Team Leader of WHO's Global Leprosy Programme, "No other disease has been more stigmatized at the personal and community level" as leprosy [8]. The account of Yu Myung-Sun [7] is a prime example of a leprosy patient suffering from stigma due to her medical condition. The word "stigma" could refer to different things here. It could focus on the discrimination against specific individuals who are different from the standard of "normal". However, it could also have more emphasis on the society and the community, and the general process involved in the evolution of the specific stigma [9]. In order to have a comprehensive understanding of stigma about leprosy, it is crucial to study not only the individual experiences of the leprosy patients but also the unjustified challenges that the Leper colony faced in a social context.

In reality, there are stigmas that are linked to a fear of diseases that cannot be defeated [9]. With leprosy, specifically, stigma is greatly associated with the perception of deformity [9]. Unfortunately, the primary cause of this stigma is the lack of accurate understanding and education of the information regarding the disease. Because the truth is, if those with the disease are advised and treated in a timely manner, they will be cured and will pose no threat to other community members [9]. However, the persisting ignorance of the general population continues to fuel the pre-established stigma until the fearful and cautious members are convinced that the "cured" patients still carry active leprosy [9].

Not only does stigma have an adverse, pervading effect on patients' lives, but it also complicates the execution of the treatment. In Nepal, after the diagnosis and start of the treatment, the patients' exposure of their condition to their immediate social community was a real threat to maintaining treatment. In some cases, patients withdrew from treatment to hide their condition [10]. Over five years, the Eastern Leprosy Control Program in Nepal reported a non-compliance rate of over $40 \%$ [11]. This is a pattern exhibited by patients in Korea as well. Due to severe discrimination and social stigma placed against them, it is inevita- 
ble for them to avoid presenting themselves to society as someone with leprosy. This also prevents early prevention and treatment of leprosy patients which aggravates the disease outcomes. Given that leprosy is a disease that can be treated without advanced symptoms with early detection, it is critical to carefully consider the social and psychological implications to eliminate leprosy as a public health problem.

\section{Difficulties Faced by Korean Leprosy Patients}

\section{1) Human Right Violation Cases}

As discussed previously, there were numerous human rights violations cases during the Japanese colonial era as well as after liberation. Around 6 thousand people with Leprosy were isolated and oppressed to work at Sorokdo while also being subjected to different bio-experiments without consent [12]. Even after the Japanese colonial era, human rights violations continued to occur in Korea [12]. These data were obtained from the Korean Federation of Hansen Associations and the International Leprosy Association. Immediately after liberation, after August 1945, there was a Sorokdo Island massacre due to the quarrel caused between the natives of the Sorokdo Island and the hospital staff to take the lead in the operation of Sorokdo Hospital [13]. 84 Leprosy patients were killed during this incident.

Another major incident was the Bitori Island massacre [13]. On August 18th, 1957, leprosy community, including the patients and the former patients, at Yeongbokwon landed on the Bitori Island to start a new community there [14]. Yeongbokwon was formerly a village that began with a small population of leprosy patients in 1949 [13]. After about 8 years, however, the village became too populated with more than 40 households [13]. Thus, new land acquisition was crucial in order to accommodate more leprosy patients [13]. A nearby island, Bitori Island, then became a prime candidate for this urgent plan which led the leper community to move there in 1957 [13]. Unfortunately, original inhabitants of the island were opposed to living in proximity with leprosy patients [13]. They caused a fire which led to the death of 26 leprosy patients and high casualties of 70 patients. Compared to the devastating casualties of the massacre, those who initiated the fire weren't punished as much [13]. The perpetrators at the time were sentenced to approximately three years in prison and the rest were released for probation only [13].

The Omado Incident was yet another instance that demonstrated unjustified human right violations against people with leprosy. After 5.16 military coup d'etat in 1961, Sorokdo Hospital and the patients were guaranteed an approval from the South Korean government to reclaim the island of Omado [11]. The initial objective for this reclamation project was to allow the people affected by leprosy to be able to return to society by reclaiming part of the land for farming purposes [11]. The overview of the project promised that 2500 leprosy patients and about 2000 families from the general public would move there, with each family obtaining about 5000 square meters of land [13]. Approximately 3000 pa- 
tients worked to build these sea walls without any support or tools. Patients carried rocks and soil by using their bare hands. However, in 1964, the oversight of this project was transferred to Jeollanamdo province which eventually brought drastic changes to the use of the land as well. The patients were no longer able to get any lands nor compensations for their labor [13].

\section{2) Individual Experiences and Challenges}

Due to the nature of the isolated and rural leper communities in Korea, lepers lived mainly in the settlements and made a living by raising cows, pigs, and chickens. Although the products from these settlements are no different than those from other communities populated by non-lepers, there was always obvious discrimination among distributors [14]. When there was a sufficient supply of the products, the goods from the leper communities are always the first ones to be avoided. The industry and the income at the settlements, therefore, could not be stable. This also meant that many of the leprosy patients have to be on the verge of bankruptcy with huge debt [14].

Majority of the leprosy patients also provided personal accounts on discrimination and stigma against their physical disfigurements. It is very common for them to be prohibited or shunned from entering public places because of their appearances. If they entered the restaurants, the owners would tell them to leave saying that they are closed for the day [14]. They couldn't even think of going to the public bathrooms or barbershops to get their haircut. They were even forced to get off the public transportations [14]. And in the worst case scenario, when they were admitted to the hospital after a car accident other patients at the hospital would be so against them staying with them that they had to be forced to leave the hospital [14]. They had to be okay with these unfair treatments just because of their medical condition.

The most tragic reality of the leprosy patients is that the discrimination is transmitted to the children of the affected patients [14]. Education and marriage become very difficult for these children. Young children of a parent with leprosy could not attend nearby elementary schools due to protests from other parents without the disease. Therefore, they had very limited access to proper education. As a result, the second generation who passed through adolescence chose to spend their youths independently, away from their parents [14]. Children chose to become orphans rather than to be called the children of leprosy patients. Many leprosy patients, therefore, were abandoned and could not even see or hear about their children again in their lifetime [14].

In the study that was supported by the Research Grant of the Korean Society of Nursing Science in 2012, life experiences of Korean leprosy patients in Sorokdo were closely investigated. In this study, five 77-year-old patients, three male and two female, were interviewed for five to six hours each over two different days [6]. The results of the study could be divided into six big theme clusters that represent their experiences with leprosy over time: bad disease approaching as fate, family breakup and wandering life, new life in Sorok Island 
hospital, treatment of Hansen's disease and disability, life in the disease community, comfort and hope of life (Table 1) [6].

\section{Korean Government's Role in Leprosy}

After the Japanese colonial era ended, the Korean government took different initiatives in order to reduce the number of people suffering from leprosy. First, the Leprosy Segregation Law was abolished in 1963. In 1982, WHO Multidrug Therapy was introduced in Korea followed by an establishment of the national standard for completion of MDT treatment in 1985 [15]. This was when the

Table 1. Life experience of patients with Hansen's disease [6].

\begin{tabular}{lll}
\hline Theme cluster & Theme & Formulated meaning \\
\hline $\begin{array}{l}\text { Bad disease } \\
\text { approaching as fate }\end{array}$ & $\begin{array}{l}\text { Negative body images and disease symptoms } \\
\text { gradually revealed } \\
\text { Stigma of lepers and society isolation }\end{array}$ & $\begin{array}{l}\text { Sense getting dull and not well-healed wound } \\
\text { Nodules, being eliminated toe, curved hand luggage } \\
\end{array}$ \\
& Missing eyebrows, crtain symptoms \\
& Being teased as a leper, being object of horror \\
& Staying at home to avoid people
\end{tabular}

Family breakup and Conflict and resentment with family, feeling of wandering life being guilty

Despair to give up the life

Wandering away far from home and painful life
Feeling guilty about becoming the pain of family

Blaming the parent due for the disease

Thoughts on death

Attempting suicide several times

Discard or abandonment by family

Experiencing discrimination and contempt when wandering around

Having a permanent goodbye to the family

Due to isolation in Sorok Island not being able to see family again Experiences of hospitality of Healthcare and peer patients

Satisfaction of not being required to hide Hansen's disease and free activities

Positive determination can be admitted about leprosy bacillus

Difficulties in admission who has history of inpatient treatment Intensive treatment, such as medication management and rehabilitation Disease progression and complications

Sequelae due to disease

Having physical disabilities

Life in the disease

community

New family

Obtaining a spouse through marriage

Constraints for the continuance of community life Getting the new family through adoption

Helping each other in living

Vasectomy for marriage

Forced abortion when pregnancy occurs

Essential to have religion to continue of community life

Comfort and hope Thanks for the comfort of the current life of life
Improvement of living conditions due to the support of country Experiences opositive changes in awareness of Hansen's disease Hope to be able to finish the rest of the life meaningfully 


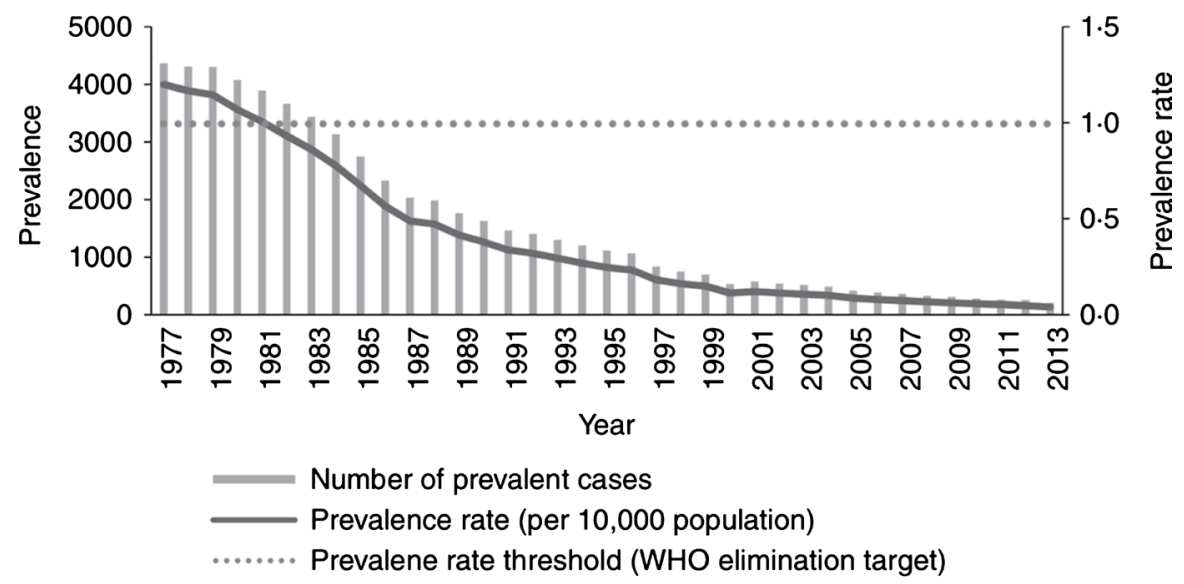

Figure 1. Registered numbers of prevalent cases and rate per 10,000 population per year in ROK 1977-2013 [15].

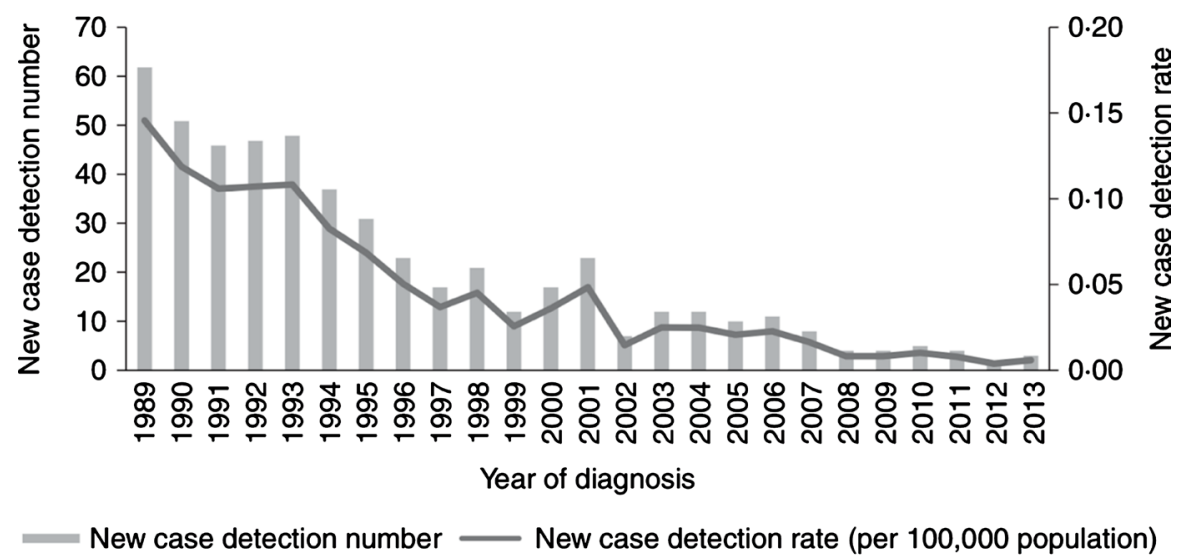

Figure 2. New case detection numbers and new case detection rates per 100,000 of population in the ROK over the years 1989-2013 [15].

patients with no symptoms and negative skin smear were excluded from the leprosy registry (Figure 1) [15]. Further efforts were taken by the Ministry of Health and Welfare (MOHW) of the Republic of Korea by recommending MDT for more than 1 year (Figure 2) [15].

Several factors have contributed to this trend.

In addition, the Korean government put in persistent effort in order to receive compensation packages from the Japanese government. In 2003, 117 Koreans requested compensation packages from the Japanese government for being institutionalized during the colonial period [16]. The initial attempts weren't successful, however, as the Japanese government rejected the requests mentioning that Koreans were not eligible for the compensation because they were not institutionalized at the sanatorium in Japan [16]. After continuous attempts of the Korean government, the Japanese government began to provide compensation packages in 2006 [16].

Around this time, new laws were established in order to protect the civil rights of the people with leprosy and increased media attention took part in spreading 
awareness of leprosy and overcoming the stigma. Also, opening up parts of the Sorokdo for the public helped reduce stigma and discrimination against people with leprosy [17]. The hospital at the island was renovated and the island was open for various volunteer groups to visit, and there were many young volunteers who came and cared for the patients [17]. Yong-Duk Kim, a woman with leprosy who has lost her hands, legs, and sight to leprosy, said that these young volunteers brought joy and dignity to older leprosy patients [17]. Additionally, these volunteers' experiences further educated the public about the disease and took part in correcting the stigma around it. The change is apparent according to Yong-Duk Kim, who said that “In the past, people couldn't and wouldn't approach us. Now all these young people come and they visit and they talk and they give me massages and they hold my hand and touch ... Some send presents. I feel very grateful and thankful when they do these things" [17].

\section{Discussion}

Despite the advances in detecting and treating leprosy, it still remains a social concern and a public health problem. It could be inferred from this that simply treating the patients with the disease is not sufficient. Although many people would have recovered from the disease itself, many of them continue to suffer from the stigmas which need to be addressed.

Many people carried stigmas against people with leprosy when they did not know much about the disease, especially whether the disease is treatable or how it's transmitted. But why are stigmas still present in the modern world where there are plenty of accessible data and studies on leprosy? Detection and treatment methods are clearly outlined and it's now known that the disease is not even transmitted easily. These facts need to be educated to the public in order to rectify the incorrect stigma from history. Compounded by the biblical references for leprosy as a curse from God, leprosy was characterized as a disease that is different in nature from other diseases. This fixed image of leprosy is clearly incorrect, but in reality, it takes quite a long time to change the public's perception. And frankly, not many people in Korea know much about the reality of the disease. If the information about leprosy has been effectively educated to the general public, many people would not have held such negative images about leprosy until today. Therefore, the reasons for severe discrimination against leprosy patients in Korea would be the lack of education about leprosy and promotion of the wellness of leprosy patients.

First of all, health professionals in Korea hold some responsibility in the creation of stigmas against leprosy patients. Although many people assume that leprosy patients receive great care and treatment, there are still many health professionals who have negative attitudes toward patients with leprosy. Some of them even refuse to treat leprosy patients. Today, there is a very limited number of leprosy specialists in Korea and many other doctors don't know much about leprosy. This problem needs to be addressed and it is necessary to initiate educa- 
tion on leprosy during the training of healthcare professionals. Healthcare professionals have a leading role in the medical communities and their attitudes matter. If the public sees them providing fair treatments to the leprosy patients, this will have a major positive effect.

Educating the public is also a very effective way of reducing discrimination against leprosy patients. Public education could be effectively done through various media. Furthermore, starting from elementary schools and middle schools, the curriculum should include education of leprosy and its history. From a young age, children should learn about the incorrect stigmas around leprosy and how they affected the patients' lives. This will facilitate the creation of a safer social atmosphere that allows the public to recognize that leprosy patients too, just like people with other diseases, have or have overcome a curable illness. Creating educational booklets about leprosy and disseminating them at schools would also aid this process.

\section{Conclusion}

Leprosy is a disease that is highly stigmatized in Korean societies. Life experiences of leprosy patients in Korea were reviewed in order to fully understand the social conditions they have faced. There is a long history of social stigma and human rights violation cases surrounding the leprosy patients in Korea, for more than 80 years. Even with advancements in treatment methods for leprosy, leprosy patients or former lepers were never "healed". For those living at Sorokdo Island, they not only had to live with incurable physical disfigurations but also emotional scars from subsequent discrimination, stigma, and endless days of isolation which continue to exist until today. Continuous efforts to reduce these stigmas through public education and media usage would be beneficial.

\section{Acknowledgements}

The authors acknowledge the Youth with Talents for sponsoring this medical project (YWT-2019-09PH).

\section{Conflicts of Interest}

The authors declare no conflicts of interest regarding the publication of this paper.

\section{References}

[1] Cole, S.T., et al. (2001) Massive Gene Decay in the Leprosy Bacillus. Nature, 409, 1007-1011. https://www.ncbi.nlm.nih.gov/pubmed/11234002

[2] WHO (2018) Leprosy. http://www.who.int/en/news-room/fact-sheets/detail/leprosy

[3] Monot, M., et al. (2005) On the Origin of Leprosy. Science, 308, 1040-1042. http://science.sciencemag.org/content/308/5724/1040.long https://doi.org/10.1126/science/1109759

[4] Scollard, D.M., Adams, L.B., Gillis, T.P., Krahenbuhl, J.L., Truman, R.W. and Wil- 
liams, D.L. (2006) The Continuing Challenges of Leprosy. Clinical Microbiology Reviews, 19, 338-381. https://doi.org/10.1128/CMR.19.2.338-381.2006

[5] Moet, F., Pahan, D., Schuring, R., Oskam, L. and Richardus, J. (2006) Physical Distance, Genetic Relationship, Age, and Leprosy Classification Are Independent Risk Factors for Leprosy in Contacts of Patients with Leprosy. The Journal of Infectious Diseases, 193, 346-353. https://doi.org/10.1086/499278

[6] Yang, Y. (2014) Life Experiences of Korean Patients with Hansens Disease in Sorok Island Hospital. Journal of Korean Academy of Nursing, 44, 639. https://doi.org/10.4040/jkan.2014.44.6.639

[7] dailymail.com (2013) Former Inmates of Korea's Brutal Leper Colony Return to Island That Has Become a Peaceful Sanctuary. https://www.dailymail.co.uk/news/article-2512729/Former-inmates-Koreas-brutal-1 eper-colony-return-island-peaceful-sanctuary.html

[8] Leprosy: Lessons to Be Learnt in Overcoming Discrimination and Stigmatization. https://www.who.int/neglected diseases/news/Leprosy lessons to be learnt/en

[9] Naaz, F., Mohanty, P.S., Bansal, A.K., Kumar, D. and Gupta, U.D. (2017) Challenges beyond Elimination in Leprosy. International Journal of Mycobacteriology, 6, 222-228. https://doi.org/10.4103/ijmy.ijmy 7017

[10] Heyland, I.E. (1940-1993) A Socia-Cultural Study of Leprosy in Nepal: Compliance, Patient Illness, Correct Patterns and Health Education. Doctoral Thesis, University of Tasmania, Hobart.

[11] Stigter, D., de Gaus, L. and Heynders, M. (2000) Leprosy: Between Acceptance and Segregation. Community Behaviour towards Persons Affected by Leprosy in Eastern Nepal. Leprosy Review, 71, 492-498. https://doi.org/10.5935/0305-7518.20000051

[12] The Korean Federation of Hansen Associations. Hansenkorea.org.

[13] International Leprosy Association-History of Leprosy. Leprosyhistory.org.

[14] Human Rights Issues Surrounding Hansen's Disease and Measures to Solve Them. Chanwoon Park, 2006 August 7th.

[15] Lee, J., Kim, J., Nishikiori, N. and Fine, P.E. (2015) The Decline of Leprosy in Republic of Korea; Patterns and Trends 1977-2013. Leprosy Review, 86, 316-327. https://doi.org/10.47276/lr.86.4.316

[16] Kim, E. (2008) Cultural Rehabilitation: Hansen's Disease, Gender, and Disability in Korea. Wagadu, 4, 108-124.

[17] MAMA ASIA, (2013) Isolation, Persecution and Peace: Life in a Korean Leper Colony.

https://www.abc.net.au/news/specials/mama-asia/2013-03-28/korea-leper-colony-so rok-island/4751018 